\title{
Modelos para estimativa da demanda de viagens de veículos de carga para supermercados e shopping-centers
}

\author{
André Gasparini'; Vânia Barcellos Gouvêa Campos²; \\ Márcio de Almeida D'agosto ${ }^{3}$
}

\begin{abstract}
Resumo: Neste trabalho apresenta-se uma proposta de modelagem da demanda de viagens de veículos de carga atraída para supermercados e shopping centers. Foram desenvolvidas equações que permitem estimar tal demanda a partir de variáveis relacionadas com as características operacionais e físicas destes empreendimentos. Pretende-se auxiliar na análise dos impactos na circulação urbana com a implantação destes pólos geradores de viagens. Para tanto, foi realizada, inicialmente, uma revisão bibliográfica sobre a demanda para estes tipos de empreendimentos que serviu de base para a escolha das variáveis que vieram a compor o questionário aplicado em 21 supermercados e 7 shopping centers da cidade do Rio de Janeiro. Com base nesta pesquisa obteve-se um perfil da movimentação dos veículos de carga para estes empreendimentos e equações de demanda de viagens atraídas para aos mesmos.
\end{abstract}

Abstract: In this work are proposed models of the travel demand of freight vehicles attracted to supermarkets and shopping centers. Equations were developed for estimating the demand of these trips related to physical and operational characteristics of these enterprises. It intends to aid in the analysis of the impacts on urban traffic with the construction of new supermarkets and shopping centers. Thus, initially it was developed a literature review on demand models for these types of enterprises to choosing the variables to compose the questionnaire which was applied in 21 supermarkets and 7 shopping centers in Rio de Janeiro city. From this research it was obtained the data and characteristics of the movement of freight vehicles for these enterprises.

\section{INTRODUÇÃO}

A preocupação em tornar as cidades mais sustentáveis e com melhor qualidade de vida está associada ao desempenho do trânsito urbano. Dentro deste contexto existem propostas de redução da circulação de veículos particulares e o incentivo ao uso do transporte público e do transporte não motorizado, como caminhadas e bicicletas.

Por outro lado, existe a questão do transporte de carga em áreas urbanas, que se faz necessário em função das diversas atividades que são desenvolvidas nas mesmas e, principalmente, para subsistência da população. Este tipo de transporte não pode deixar de existir, mas pode ser planejado de forma que impacte menos a circulação urbana.

Entre as várias atividades comerciais que geram movimentação de veículos de carga, têm-se os shopping centers e supermercados que se caracterizam como Pólos Geradores de Viagem (PVG). Estes são empreendimentos que independente de seu tamanho ou características são pólos de atração de viagens, tan-

\footnotetext{
${ }^{1}$ André Gasparini, Pós-graduação em Engenharia de Transportes, Instituto Militar de Engenharia, Rio de Janeiro, RJ, Brasil. (e-mail: andregasparini@hotmail.com).

${ }^{2}$ Vânia Barcellos Gouvêa Campos, Pós-graduação em Engenharia de Transportes, Instituto Militar de Engenharia, Rio de Janeiro, RJ, Brasil. (e-mail: vania@ime.eb.br).

${ }^{3}$ Márcio de Almeida D'agosto, Programa de Engenharia de Transportes, Instituto Alberto Luiz Coimbra de Pós-Graduação e Pesquisa de Engenharia, Universidade Federal do Rio de Janeiro, Rio de Janeiro, RJ, Brasil. (e-mail: dagosto@pet.coppe.ufrj.br).
}

Manuscrito recebido em 29/1/2010 e aprovado para publicação em 10/3/2010. Este artigo é parte de TRANSPORTES, volume XVIII, número 1,março de 2010. ISSN: 2237-1346 (online). to de pessoas quanto de carga. Sendo assim, quando da sua implantação devem ser analisados os impactos que esta movimentação de pessoas e cargas pode causar no sistema viário de acesso e no entorno destes empreendimentos. Para tanto, faz-se necessário o desenvolvimento de modelos que possam fazer uma estimativa desta movimentação.

Pesquisas visando a modelagem de viagens atraídas para Pólos Geradores de Viagens têm sido mais desenvolvidas com foco nos veículos de passeio, por ser esta movimentação, dependendo do empreendimento, em maior escala e, conseqüentemente, de maior impacto na circulação. Porém a circulação de veículos de carga por seu tamanho e a necessidade algumas vezes de realização da carga e descarga na própria via acarretam transtornos, principalmente, na área de entorno do empreendimento.

Desta forma, a partir de uma pesquisa realizada num conjunto de supermercados e de shopping centers do Rio de Janeiro, desenvolveu-se uma modelagem da demanda de viagens para estes empreendimentos relacionadas com os veículos de carga.

Na $2^{a}$ seção deste trabalho apresenta-se o procedimento de pesquisa que subsidia o desenvolvimento do modelo, enquanto nas duas seções subseqüentes ( $3^{\mathrm{a}}$ e $4^{\mathrm{a}}$ ) apresentam-se os modelos para shopping centers e supermercados. Na $5^{\text {a }}$ seção encontram-se as conclusões do artigo.

\section{PROCEDIMENTO DE PESQUISA}

No estudo de Portugal e Goldner (2003), foram encontrados poucos trabalhos relacionados com a mode- 
lagem da demanda de veículos de carga. No contexto geral, ou seja, para todo tipo de ocupação do solo e atividades em urbanas, destacam-se os estudos de Hutchinson (1974), Ogden (1992) e ITE (1995). Além destes, há um estudo realizado no Rio de Janeiro por Melo (2002) que compreende a modelagem da demanda de viagens de veículos de carga para um conjunto de empreendimentos de varejo que inclui supermercados pequenos, considerados micropólos. Silva e Waisman (2007) desenvolveram estudo para demanda de viagens de veículos de carga para bares e restaurantes em São Paulo.

Os modelos desenvolvidos nestes estudos utilizavam o método de regressão simples e múltipla para um conjunto de variáveis explicativas. Dentre estas variáveis destacam-se: área construída e número de funcionários como as mais utilizadas. A Tabela 1 apresenta um resumo das equações resultantes destes estudos, que têm coeficiente de determinação $\left(R^{2}\right)$ acima de 0,60.

A partir da revisão bibliográfica, foram identificadas as variáveis que poderiam influenciar na demanda de viagens. Estas variáveis compuseram um questionário aplicado num conjunto de 7 shopping centers e 21 supermercados na cidade do Rio de Janeiro (Gasparini, 2008) coletando dados de viagens durante uma semana. Estes estabelecimentos forneceram também informações que permitiram obter um perfil da movimentação destes veículos.

Uma das formas de modelagem da demanda de viagens compreende a utilização do método de regressão linear conforme observado na revisão bibliográfica. Neste tipo de modelagem se procura estabelecer uma relação entre a variável dependente (número de viagens) com as características socioeconômicas e de uso do solo, quando se avalia uma região e com as características físicas e socioeconômicas quando se avalia um empreendimento como um supermercado ou shopping center.

Neste estudo a variável dependente está relacionada com as viagens de veículos de carga, mais especificamente, com as viagens atraídas para o empreendimento. Para tanto foram definidas as possíveis variáveis a serem pesquisadas para estabelecer uma relação com a variável dependente de forma que se pudesse obter um modelo que fizesse uma estimativa aproximada da demanda deste tipo de veículos para um supermercado ou um shopping center a ser implantado.

Para a definição do tamanho da amostra de supermercados a serem pesquisados, tomou-se como base o relatório de geração de viagens do ITE (2001), onde requisitos são estabelecidos e foram tomados como parâmetros para esta definição. O relatório do ITE (2001) recomenda que a pesquisa seja realizada num intervalo mínimo entre 3 e 5 estabelecimentos para obtenção das taxas médias de geração de viagens em determinado local, levando-se em consideração a dificuldade que se encontra em se efetivar uma pesquisa. É sugerido ainda pelo ITE (2001) que os estabelecimentos e os locais onde estes se encontram instalados devam ter no mínimo 2 anos de existência.

\section{ANÁLISE DA DEMANDA DE VIAGENS DE CARGA - SUPERMERCADOS}

Como existem diferentes categorias de supermercado, procurou-se desenvolver uma pesquisa que envolvesse um conjunto de empreendimentos nas diferentes categorias. Para tanto, foi inicialmente realizada uma consulta à Associação Brasileira de Supermercados

Tabela 1. Modelos de demanda de Viagens de veículos de carga

\begin{tabular}{|c|c|c|}
\hline Autor & Equação & Variáveis \\
\hline Hutchinson (1974) & $Y=2,24+0,10 X_{2}+0,39 X_{1}$ & $\begin{array}{ll}\mathrm{Y}: & \text { número de viagens atraídas diariamente; } \\
\mathrm{X}_{1}: & \text { total de caminhões próprios da empresa; } \\
\mathrm{X}_{2}: & \text { volume de produtos manufaturados; }\end{array}$ \\
\hline \multirow[t]{2}{*}{ Ogden (1992) } & $Y=-391+0,0894 X_{1}+0,0158 X_{2}$ & $\begin{array}{ll}\mathrm{Y}: & \begin{array}{l}\text { mercadorias atraídas por zona de tráfego, em } \\
\text { toneladas; }\end{array} \\
\mathrm{X}_{1}: & \begin{array}{l}\text { número de empregados no nível de apoio } \\
\text { (operários) na zona; }\end{array} \\
\mathrm{X}_{2}: & \text { número de domicílios na zona de tráfego } \\
\end{array}$ \\
\hline & $Y=13,97+0,044 X$ & $\begin{array}{l}\text { Y: carregamentos semanais totais por planta; } \\
\mathrm{X}: \quad \text { área total por pavimento }\end{array}$ \\
\hline \multirow{2}{*}{ ITE (1995) } & $\mathrm{Y}=\mathrm{X}_{1}+8,96$ & $\begin{array}{l}\text { Y: Viagens diárias de caminhões em dias úteis em } \\
\text { terminais de caminhões }\end{array}$ \\
\hline & $Y=2,06 X_{2}-3,44$ & $\begin{array}{ll}\mathrm{X}_{1}: & \text { número de docas dos terminais } \\
\mathrm{X}_{2}: & \text { número de empregados }\end{array}$ \\
\hline Melo (2002) & $Y=0,9260+0,0010 X_{1}$ & $\begin{array}{ll}\mathrm{Y}: & \text { volume de viagens de veículos de carga } \\
\mathrm{X}_{1:} & \text { área construída de cada empreendimento. }\end{array}$ \\
\hline Silva e Waisman (2007) & $Y=2,07422+0,01670 X_{1}+0,96704 X_{2}$ & $\begin{array}{ll}\mathrm{Y}: & \text { viagens de caminhões por semana } \\
\mathrm{X}_{1}: & \text { área dos estabelecimentos } \\
\mathrm{X}_{2}: & \text { número de funcionários }\end{array}$ \\
\hline
\end{tabular}


(ABRAS) e à Associação de Supermercados do Rio de Janeiro (ASSERJ).

A ABRAS classifica os supermercados de acordo com suas características, variedade de produtos comercializados e tamanhos, como: (1) hipermercados empreendimentos de maior porte com área de vendas superior a $5.000 \mathrm{~m}^{2}$, mais de 50 check-outs e uma média de 45 mil itens à venda. Contando com as seções de mercearia, hortifrutigranjeira, açougue, frios, laticínios, peixaria, padaria, bazar, têxteis e eletroeletrônicos com grande variedade de produtos e volume de vendas; (2) super-lojas ou grandes supermercados aqueles com uma área de vendas entre 2.501 a 5.000 $\mathrm{m}^{2}$, possuindo 21 a 30 check-outs e com foco principal em produtos alimentícios, oferecendo também têxteis e eletrônicos com uma média total de 20 mil itens e (3) convencionais - empreendimentos de porte médio com característica principal de uma loja de alimentos com boa variedade de produtos em seções de mercearia, hortifrutigranjeira, açougue, frios e laticínios, peixaria, padaria e bazar com uma média de 12 mil itens. Sua área de vendas tem variação de 1.001 a $2.500 \mathrm{~m}^{2}$ e possui de 8 a 20 check-outs.

O questionário aplicado em cada um dos estabelecimentos compreendeu um conjunto de informações que estão descritas na Tabela 2. Estas informações permitiram obter dados da demanda e do perfil do estabelecimento quanto as suas características físicas e operacionais.

Tabela 2. Informações solicitadas na pesquisa

\begin{tabular}{l|l}
\hline Horário de funcionamento; & Área de vendas (AV); \\
\hline $\begin{array}{l}\text { Se o empreendimento faz } \\
\text { parte de uma rede; }\end{array}$ & Área total construída (AC); \\
\hline Se possui lojas anexas; & Área total do terreno (AT); \\
\hline Se possui posto de gasolina; & Vagas carga/descarga; \\
\hline $\begin{array}{l}\text { Se possui restaurantes/praça } \\
\text { de alimentação; }\end{array}$ & $\begin{array}{l}\text { Vagas estacionamento para } \\
\text { clientes; }\end{array}$ \\
\hline $\begin{array}{l}\text { Se possui caixas ou } \\
\text { agências bancárias; }\end{array}$ & Número de funcionários; \\
\hline $\begin{array}{l}\text { Número de itens } \\
\text { comercializados; }\end{array}$ & Número médio clientes/dia; \\
\hline
\end{tabular}

Quanto ao fluxo de veículos de carga, procurou-se obter informações do tipo: quantidade de veículos diários (durante a semana analisada) atraídos para o empreendimento, tipos e portes.

As visitas para estes estabelecimentos foram realizadas, em sua totalidade, dentro do mês de setembro de 2007, sendo a pesquisa direcionada para a obtenção dos dados de volume da semana de 24 a 30 do mês.

A escolha dos supermercados para realização da pesquisa se baseou no porte e localização, definindose que seriam investigadas, inicialmente, 10 do universo de 15 grandes redes de supermercados existen- tes no Rio de Janeiro. Deste conjunto de redes de grandes redes de supermercados, 7 se dispuseram a responder ao questionário que foi aplicado num conjunto de 21 estabelecimentos. Um resumo do resultado desta pesquisa é apresentado na Tabela 3 , onde as letras A, B, C, D, E, F e G foram utilizadas para definir as 7 redes as quais as filiais pertencem.

A partir das respostas ao questionário e da observação no local pode-se verificar que independente da sua classificação, os supermercados apresentam as seguintes características de movimentação de veículos de carga: (1) o dia de maior volume de viagens às sextasfeiras com 71,5\% das observações; (2) o veículo que mais freqüenta este empreendimento é do tipo caminhão (73,85 \% em média), seguido de vans e furgões em todos os estabelecimentos estudados; (3) os caminhões que mais fazem entregas aos supermercados são do tipo pequeno e médio (caminhão simples de 2 e 3 eixos) e (4) o sábado e domingo são dias atípicos de entregas sendo estas mínimas e eventuais e quase nulas aos domingos.

Outros aspectos relevantes para o planejamento do transporte de cargas citados pelos entrevistados foram quanto ao supermercado possuir ou não um depósito próprio: (1) quando o supermercado não possui depósito, no caso apenas as filiais classificadas como convencionais $\mathrm{A} 1$ e $\mathrm{B} 1$, o comportamento das viagens ocorre com maior volume no início da semana, geralmente nas segundas e terças-feiras no período da manhã; (2) quando o supermercado possui depósito, no caso das demais filiais analisadas, o maior volume de viagens ocorre sextas-feiras (com 79\% das observações) e no período da tarde segundo informações obtidas na pesquisa realizada junto aos representantes dos supermercados.

Observa-se, a partir dos dados da Tabela 3, uma média de aproximadamente 25 viagens de veículos de carga por supermercado na semana estudada. Por categoria, tem-se em média: 30 viagens atraídas para os hipermercados, 24 para as super-lojas e 20 para os supermercados convencionais. Nota-se assim, uma relação de número de viagens proporcional ao porte do supermercado.

Para se obter a modelagem da demanda de viagens por veículos de carga, foram inicialmente realizadas análises dos índices de correlação linear entre a variável dependente (volume de viagens de veículos de carga) e as demais variáveis independentes e, também, entre as variáveis independentes. As variáveis independentes analisadas foram: $\left(\mathrm{X}_{1}\right)$ área do terreno $\left[\mathrm{m}^{2}\right]$; $\left(\mathrm{X}_{2}\right)$ área construída $\left[\mathrm{m}^{2}\right] ;\left(\mathrm{X}_{3}\right)$ área de vendas $\left[\mathrm{m}^{2}\right]$; $\left(\mathrm{X}_{4}\right)$ número total de lojas; $\left(\mathrm{X}_{5}\right)$ número total de vagas de estacionamento de veículos de passeio; $\left(\mathrm{X}_{6}\right)$ volume médio de clientes por dia e $\left(\mathrm{X}_{7}\right)$ número médio de funcionários. 
Tabela 3. Informações resultantes da pesquisa realizada

\begin{tabular}{|c|c|c|c|c|c|c|c|c|}
\hline \multirow{2}{*}{ Categoria } & \multicolumn{8}{|c|}{ Variáveis } \\
\hline & $Y^{1}$ & $X_{1}^{2}$ & $X 2^{3}$ & $X_{3}{ }^{4}$ & $X_{4}^{5}$ & $X_{5}^{6}$ & $X_{6}{ }^{7}$ & $X_{7}^{8}$ \\
\hline Hiper A6 & 30 & 8930 & 6100 & 5840 & 20 & 380 & 9200 & 246 \\
\hline Hiper B3 & 33 & 9360 & 6570 & 6230 & 17 & 350 & 9600 & 256 \\
\hline Hiper C2 & 28 & 8300 & 6025 & 5800 & 25 & 380 & 6500 & 236 \\
\hline Hiper D2 & 25 & 9265 & 5950 & 5732 & 20 & 300 & 3000 & 221 \\
\hline Hiper E3 & 34 & 11890 & 7950 & 7300 & 15 & 375 & 6800 & 260 \\
\hline Hiper F3 & 38 & 10645 & 7155 & 6340 & 12 & 350 & 9300 & 235 \\
\hline Hiper G1 & 23 & 9865 & 5890 & 5630 & 15 & 300 & 4350 & 187 \\
\hline Hiper G2 & 27 & 10540 & 8600 & 7240 & 20 & 350 & 5100 & 218 \\
\hline Super-loja A4 & 24 & 3250 & 2930 & 2780 & 8 & 120 & 6600 & 167 \\
\hline Super-loja A5 & 30 & 4300 & 3670 & 3204 & 5 & 200 & 7500 & 194 \\
\hline Super-loja C1 & 20 & 5200 & 3980 & 3630 & 10 & 150 & 5300 & 187 \\
\hline Super-loja D1 & 22 & 4970 & 3100 & 3100 & 10 & 158 & 1800 & 180 \\
\hline Super-loja E2 & 24 & 5150 & 2980 & 2980 & 5 & 153 & 4600 & 173 \\
\hline Super-loja F1 & 27 & 4405 & 3480 & 3220 & 8 & 200 & 6900 & 175 \\
\hline Super-loja F2 & 24 & 6640 & 3970 & 3970 & 5 & 260 & 8000 & 202 \\
\hline Convencional A1 & 13 & 1950 & 1670 & 1310 & 0 & 12 & 3100 & 80 \\
\hline Convencional A3 & 16 & 1780 & 1590 & 1370 & 0 & 20 & 3500 & 90 \\
\hline Convencional B1 & 27 & 2420 & 2330 & 2100 & 0 & 40 & 4300 & 144 \\
\hline Convencional B2 & 19 & 1850 & 1680 & 1610 & 0 & 28 & 3800 & 130 \\
\hline Convencional A2 & 20 & 2130 & 1960 & 1820 & 0 & 70 & 4000 & 120 \\
\hline Convencional E1 & 26 & 3120 & 2460 & 2320 & 5 & 102 & 3800 & 150 \\
\hline
\end{tabular}

Notas: 1 - total de viagens na semana, 2 - área total $(\mathrm{AT})\left[\mathrm{m}^{2}\right], 3$ - área construída (AC) [m²], área de vendas (AV) [m²],

5 - número de lojas, 6 - vagas de estacionamento, 7 - número médio de clientes por dia, 8 - número de funcionários

Verificou-se na análise de correlação linear que as variáveis que apresentaram melhor correlação com a variável dependente foram: $\mathrm{X}_{3}, \mathrm{X}_{5}, \mathrm{X}_{6}$ e $\mathrm{X}_{7}$. Sendo assim, essas variáveis foram indicadas para modelagem da demanda com o método de regressão linear. Foi verificada a correlação entre elas o que resultou na utilização de apenas duas variáveis na equação. Não foi possível a utilização de três ou mais, uma vez que os coeficientes de correlação entre algumas as variáveis independentes foram muito altos, não sendo, portanto, indicado a utilização das mesmas numa mesma equação. As Tabelas 4 e 5 apresentam as equações obtidas considerando-se primeiramente as viagens de todos os tipos de veículos de carga e, em seguida, somente para caminhões. As equações foram também definidas para diferentes períodos de demanda de viagens: semana, dia pico e dia fora do pico. Fez-se uma tentativa de modelagem da demanda de viagens por categoria de supermercado, não se encontrando um resultado satisfatório para o coeficiente de determinação $\left(\mathrm{R}^{2}\right)$ e valores p e t.

Dentre as equações obtidas, destacam-se aquelas com os melhores coeficientes $\mathrm{R}^{2}$, dentro de cada análise efetuada: equações (1), (3), (4), (7), (10) e (14). As equações apresentaram coeficientes estatisticamente significativos (quando da análise dos testes t e valor- $p$ ) com níveis de confiança variando entre $95 \%$ e $99 \%$. Desta forma, considera-se que as mesmas poderão ser indicadas para estimar a demanda de veículos de carga para supermercados, porém, a preferência se faz sobre aquelas que apresentaram coeficientes de determinação maior que 0,7 (Stevenson, 1981). 
Tabela 4. Modelos de demanda considerando todos os veículos de carga

\begin{tabular}{|c|c|c|c|c|}
\hline Variável dependente $(\mathrm{Y})$ & Variável independente $\left(X_{i}\right)$ & Equação & $R^{2}$ & \\
\hline Volume de veículos na semana & $\begin{array}{ll}\mathrm{X}_{6}: & \text { volume médio de clientes } \\
\mathrm{X}_{7}: & \text { número de funcionários } \\
\end{array}$ & $\mathrm{Y}_{\mathrm{T}}=7,35+0,00087 \mathrm{X}_{6}+0,712 \mathrm{X}_{7}$ & 0,754 & (1) \\
\hline Volume de veículos na semana & $\begin{array}{ll}\mathrm{X}_{5}: & \text { vagas de estacionamentos } \\
\mathrm{X}_{6}: & \text { volume médio de clientes } \\
\end{array}$ & $\mathrm{Y}_{\mathrm{T}}=14,39+0,02147 \mathrm{X}_{5}+0,0012 \mathrm{X}_{6}$ & 0,680 & $(2)$ \\
\hline Volume de veículos no dia pico & $\begin{array}{ll}\mathrm{X}_{6}: & \text { volume médio de clientes } \\
\mathrm{X}_{7}: & \text { número de funcionários } \\
\end{array}$ & $Y_{P}=3,51+0,00095 X_{7}+0,00023 X_{6}$ & 0,664 & (3) \\
\hline $\begin{array}{l}\text { Volume médio de veículos fora } \\
\text { do dia pico }\end{array}$ & $\begin{array}{ll}\mathrm{X}_{6}: & \text { volume médio de clientes } \\
\mathrm{X}_{7}: & \text { número de funcionários }\end{array}$ & $Y_{\mathrm{FP}}=1,08+5,77\left(\mathrm{E}^{-5}\right) \mathrm{X}_{6}+0,00118 \mathrm{X}_{7}$ & 0,650 & (4) \\
\hline $\begin{array}{l}\text { Volume médio de veículos fora } \\
\text { do dia pico }\end{array}$ & $\begin{array}{ll}\mathrm{X}_{5}: & \text { vagas de estacionamentos } \\
\mathrm{X}_{6}: & \text { volume médio de clientes } \\
\end{array}$ & $Y_{\mathrm{FP}}=2,25+0,00344 \mathrm{X}_{5}+0,00011 \mathrm{X}_{6}$ & 0,543 & (5) \\
\hline $\begin{array}{l}\text { Volume médio de veículos fora } \\
\text { do dia pico }\end{array}$ & $\begin{array}{ll}\mathrm{X}_{3}: & \text { área de vendas } \\
\mathrm{X}_{6}: & \text { volume médio de clientes }\end{array}$ & $\mathrm{Y}_{\mathrm{FP}}=1,93+0,00023 \mathrm{X}_{3}+0,00013 \mathrm{X}_{6}$ & 0,576 & (6) \\
\hline
\end{tabular}

Tabela 5. Modelos de demanda considerando somente caminhões

\begin{tabular}{|c|c|c|c|c|}
\hline Variável dependente $(Y)$ & Variável independente $\left(X_{i}\right)$ & Equação & $R^{2}$ & \\
\hline Volume de veículos na semana & $\begin{array}{ll}\mathrm{X}_{6}: & \text { volume médio de clientes } \\
\mathrm{X}_{7}: & \text { número de funcionários } \\
\end{array}$ & $\mathrm{Y}_{\mathrm{T}}=3,59+0,00030 \mathrm{X}_{6}+0,710 \mathrm{X}_{7}$ & 0,796 & (7) \\
\hline Volume de veículos na semana & $\begin{array}{ll}\mathrm{X}_{5}: & \text { vagas de estacionamentos } \\
\mathrm{X}_{6}: & \text { volume médio de clientes }\end{array}$ & $\mathrm{Y}_{\mathrm{T}}=10,62+0,026 \mathrm{X}_{5}+0,00421 \mathrm{X}_{6}$ & 0,781 & (8) \\
\hline Volume de veículos no dia pico & $\begin{array}{ll}\mathrm{X}_{5}: & \text { vagas de estacionamentos } \\
\mathrm{X}_{7}: & \text { número de funcionários } \\
\end{array}$ & $\mathrm{Y}_{\mathrm{P}}=2,63+0,00172 \mathrm{X}_{5}+0,00867 \mathrm{X}_{7}$ & 0,516 & (9) \\
\hline $\begin{array}{l}\text { Volume médio de veículos fora } \\
\text { do dia pico }\end{array}$ & $\begin{array}{ll}\mathrm{X}_{5}: & \text { vagas de estacionamentos } \\
\mathrm{X}_{6}: & \text { volume médio de clientes } \\
\end{array}$ & $\mathrm{Y}_{\mathrm{FP}}=2,99+0,03 \mathrm{X}_{5}+0,00016 \mathrm{X}_{6}$ & 0,594 & $(10)$ \\
\hline $\begin{array}{l}\text { Volume médio de veículos fora } \\
\text { do dia pico }\end{array}$ & $\begin{array}{l}\mathrm{X}_{7}: \text { número de funcionários } \\
\mathrm{X}_{3} \text { :área de vendas }\end{array}$ & $\mathrm{Y}_{\mathrm{FP}}=0,64+0,0054 \mathrm{X}_{7}+0,00016 \mathrm{X}_{3}$ & 0,828 & $(11)$ \\
\hline $\begin{array}{l}\text { Volume médio de veículos fora } \\
\text { do dia pico }\end{array}$ & $\begin{array}{ll}\mathrm{X}_{6}: & \text { volume médio de clientes } \\
\mathrm{X}_{7}: & \text { número de funcionários } \\
\end{array}$ & $\mathrm{Y}_{\mathrm{FP}}=0,23+2,34\left(\mathrm{E}^{-5}\right) \mathrm{X}_{6}+0,0104 \mathrm{X}_{7}$ & 0,795 & $(12)$ \\
\hline $\begin{array}{l}\text { Volume médio de veículos fora } \\
\text { do dia pico }\end{array}$ & $\begin{array}{ll}\mathrm{X}_{5}: & \text { vagas de estacionamentos } \\
\mathrm{X}_{6}: & \text { volume médio de clientes } \\
\end{array}$ & $Y_{\mathrm{FP}}=1,27+0,00382 \mathrm{X}_{5}+4,19\left(\mathrm{E}^{-5}\right) \mathrm{X}_{6}$ & 0,775 & $(13)$ \\
\hline $\begin{array}{l}\text { Volume médio de veículos fora } \\
\text { do dia pico }\end{array}$ & $\begin{array}{ll}\mathrm{X}_{3}: & \text { área de vendas } \\
\mathrm{X}_{6}: & \text { volume médio de clientes }\end{array}$ & $\mathrm{Y}_{\mathrm{FP}}=0,92+0,00025 \mathrm{X}_{3}+6,54\left(\mathrm{E}^{-5}\right) \mathrm{X}_{6}$ & 0,836 & (14) \\
\hline
\end{tabular}

Observa-se ainda que as variáveis que aparentemente têm grande influência na estimativa da demanda de veículos de carga para os supermercados são o volume médio de clientes por dia $\left(\mathrm{X}_{6}\right)$ e o número de funcionários $\left(\mathrm{X}_{7}\right)$.

\section{ANÁLISE DA DEMANDA DE VIAGENS DE CARGA - SHOPPING-CENTERS}

Para análise da demanda de viagens para shopping centers foram consideradas algumas das variáveis utilizadas no caso dos supermercados, além de outras, específicas para estes empreendimentos, como por exemplo, o número de lojas e o número de lojas âncoras.

Para efetivação da pesquisa nos shopping centers, fez-se inicialmente uma consulta à Associação Brasileira de shopping centers (ABRASCE) onde, das 30 (tinta) unidades localizadas no Rio de Janeiro, selecionou-se as 12 (doze) com maior área bruta locável. Todas foram contatadas e visitadas, porém as respostas ao questionário foram obtidas para 7 estabelecimentos. No questionário aplicado nos shopping centers buscaram-se as informações apresentadas na Tabela 6 .

Os estabelecimentos também foram questionados quanto ao número de vagas e locais para carga e descarga, se havia áreas destinadas para tal e se estas eram consideradas ideais ou não. Quanto ao volume de veículos de carga, procurou-se obter informações do tipo: quantidade de veículos diários (durante a semana analisada) que chegam ao empreendimento, seus tipos e porte.

Em relação à movimentação de veículos foi feita uma coleta de informações referente a dois períodos pré-definidos: uma semana dentro do mês de dezembro de 2006 (semana de 18 à 24), onde o movimento é considerado grande (pico) em virtude de ocorrência

Tabela 6. Resumo das informações solicitadas aos empreendimentos

\begin{tabular}{l|l}
\hline Nome do empreendimento; & $\begin{array}{l}\text { Se possui restaurantes/praça } \\
\text { de alimentação; }\end{array}$ \\
\hline Horário de funcionamento; & $\begin{array}{l}\text { Se possui caixas ou agências } \\
\text { bancárias; }\end{array}$ \\
\hline Número de Funcionários; & Área bruta locável (ABL); \\
\hline Número médio clientes/dia; & Área total construída (ATC); \\
\hline Número de Lojas; & Área total do terreno (ATT); \\
\hline $\begin{array}{l}\text { Se o empreendimento faz } \\
\text { parte de uma rede; }\end{array}$ & $\begin{array}{l}\text { Vagas estacionamento para } \\
\text { clientes; }\end{array}$ \\
\hline $\begin{array}{l}\text { Se possui stands em seu } \\
\text { interior; }\end{array}$ & Vagas carga/descarga. \\
\hline Se possui posto de gasolina; & \\
\hline
\end{tabular}


das festas de fim de ano e, consequentemente, de um consumo maior; e uma semana no mês de março de 2007 (semana de 05 à 11) historicamente observado com movimentações normais.

Também foi observada a movimentação dos veículos de carga, quando da sua operação, nos dias da visita/entrevista local. Este período, muitas vezes, era coincidente com o dia de maior movimentação (pico) de veículos de carga.

A Tabela 7 apresenta um resumo das informações após a aplicação do questionário nos empreendimentos, constando algumas de suas características físicas e o volume de total de viagens de veículos de carga atraídos nas semanas de análise. Observe-se que os sete shopping centers receberam uma denominação, sendo chamados de "Shopping A, B, C, D, E, F e G". Destes, o Shopping B se insere na categoria "comunitário" e os demais como "regionais".

Os shoppings centers classificados como regionais, são empreendimentos construídos especificamente para as atividades planejadas quando de sua concepção, ou seja, de ser um shopping center. Os depósitos destas edificações são de porte consideravelmente maior, quando comparados aos classificados como comunitários e por isto preparados para receber um volume maior de mercadorias e consequentemente de veículos de carga para seu suprimento. Esta também é uma característica da sua área de carga/descarga e manobra, evitando-se que haja espera de veículos nas vias públicas no entorno do estabelecimento, principalmente em dias de maior pico.

Nos shopping centers regionais, devido as suas características, observou-se a incidência de viagens de veículos com volumes de carga maiores. Isto ocorreu para os dois períodos tomados como base, próximos aos finais de semana e com maior freqüência às sextas-feiras.

Neste trabalho, o shopping center denominado B é o único que recebe a classificação de comunitário, e possui assim um comportamento de viagens diferente dos demais. Trata-se de uma adaptação de uma edificação preparada originalmente para comportar uma única loja de departamentos. Por não ser inicialmente concebido para abrigar um shopping center, o empreendimento possui um depósito e uma área de carga/descarga considerados de pequeno porte para suportar a demanda de diferentes tipos de lojas e mercadorias. Devido a estas características, apresenta um volume de viagens de veículos de carga maior que os demais no início da semana, para suprimento dos estoques das lojas para vendas durante o restante da semana. Este fator faz também com que muitas vezes haja espera de veículos nas vias públicas no entorno do estabelecimento em dias de pico de entrega, que para este caso ocorre às terças-feiras.

Constatou-se, numa análise geral, que independente da classificação ou de onde estejam localizados, os empreendimentos do tipo shopping center estudados apresentam as seguintes características: (1) o dia de maior volume (pico) de viagens é a sexta-feira com $57,2 \%$ das observações, exceto no shopping center denominado $\mathrm{B}$, que devido às suas características, o maior volume médio de viagens ocorre às terçasfeiras; (2) o veículo de carga mais utilizado é do tipo caminhão (47,43 \% em média) seguido de vans e furgões para todos os empreendimentos estudados; (3) os caminhões que mais efetivam entregas a estes shopping center são do tipo pequeno e médio (caminhão simples de 2 e 3 eixos); (4) domingo é um dia atípico de entregas, sendo estas mínimas e eventuais, podendo considerá-lo sempre como o dia de menor quantidade de viagens; (5) o maior número de viagens de veículos de carga ocorre pelas manhãs, segundo informações obtidas na pesquisa realizada junto aos representantes dos shopping center; (6) não foram computadas viagens para entregas eventuais solicitadas pelos lojistas e que não utilizem a área operacional de carga/descarga dos estabelecimentos e (7) observou-se que no período próximo ao Natal há um aumento de aproximadamente $45 \%$ das viagens

Para modelagem da demanda de viagens por veículos de carga, foram inicialmente realizadas análises dos índices de correlação linear entre a variável dependente $\left(\mathrm{Y}_{1}\right)$ e as variáveis independentes, bem como

Tabela 7. Viagens atraídas nas semanas pesquisadas e características dos shopping centers

\begin{tabular}{|c|c|c|c|c|c|c|}
\hline \multicolumn{2}{|c|}{ Classe } & \multirow{2}{*}{$\begin{array}{l}\boldsymbol{Y}_{1}^{1} \\
431 \\
\end{array}$} & \multirow{2}{*}{$\begin{array}{c}Y_{2}{ }^{2} \\
316 \\
\end{array}$} & \multirow{2}{*}{$\begin{array}{c}\boldsymbol{X}_{\mathbf{1}}{ }^{\mathbf{3}} \\
21827 \\
\end{array}$} & \multirow{2}{*}{$\begin{array}{c}\boldsymbol{X}_{2}{ }^{3} \\
130960 \\
\end{array}$} & \multirow{2}{*}{$\begin{array}{c}\boldsymbol{X}_{3}{ }^{5} \\
50000 \\
\end{array}$} \\
\hline Regional & A & & & & & \\
\hline Comunitário & $\mathrm{B}$ & 257 & 218 & 5700 & 57610 & 15600 \\
\hline Regional & $\mathrm{C}$ & 332 & 238 & 120006 & 75835 & 69312 \\
\hline Regional & $\mathrm{D}$ & 321 & 220 & 218569 & 193830 & 70000 \\
\hline Regional & $E$ & 399 & 192 & 24552 & 93200 & 26443 \\
\hline Regional & $\mathrm{F}$ & 253 & 164 & 127881 & 81000 & 40653 \\
\hline \multirow[t]{2}{*}{ Regional } & $\mathrm{G}$ & 333 & 254 & 113000 & 201000 & 77100 \\
\hline & Totais: & 2326 & 1602 & & & \\
\hline
\end{tabular}

Notas: Y1 - número total de viagens por veículos de carga em 18-24/12/2006,Y2 - número total de viagens de veículo de carga em 05-11/03/2007, X1 - área total do terreno (ATT) [m²], X2 - área total construída (ATC) [m²], X3 - área bruta locável (ABL) $\left[\mathrm{m}^{2}\right]$. 
da correlação das variáveis independentes entre si. Foram consideradas para efeito desta análise 10 variáveis independentes: $\left(\mathrm{X}_{1}\right)$ área total do terreno (ATT) $\left[\mathrm{m}^{2}\right]$; $\left(\mathrm{X}_{2}\right)$ área total construída (ATC) $\left[\mathrm{m}^{2}\right] ;\left(\mathrm{X}_{3}\right)$ área bruta locável (ABL) $\left[\mathrm{m}^{2}\right]$; $\left(\mathrm{X}_{4}\right)$ número total de lojas; $\left(\mathrm{X}_{5}\right)$ número total de lojas satélite; $\left(\mathrm{X}_{6}\right)$ número total de lojas âncora; $\left(\mathrm{X}_{7}\right)$ número total de salas comerciais; $\left(\mathrm{X}_{8}\right)$ número total de vagas de estacionamento de veículos de passeio; $\left(\mathrm{X}_{9}\right)$ volume médio de clientes por dia; $\left(\mathrm{X}_{10}\right)$ número médio de funcionários.

Nas análises de correlação linear observou-se que as variáveis independentes possuem uma baixa correlação com a variável dependente. Mesmo assim, foram utilizadas as que apresentaram maior correlação na amostra, ou seja: $X_{2}, X_{3}, X_{4}, X_{6}, X_{7}, X_{8}$ e $X_{9}$. Como algumas delas tinham alta correlação entre si, definiu-se a utilização primeiramente de apenas duas e, posteriormente, de três variáveis explicativas na análise de regressão.

Foram realizadas análises considerando três variáveis dependentes (uma por vez): $\left(\mathrm{Y}_{1} / \mathrm{Y}_{2}\right)$ o volume total de viagens na semana; ( $\left.\mathrm{YP}_{1} / \mathrm{YP} 2\right)$ o volume de viagens considerando somente o dia de maior pico e $\left(\mathrm{YM}_{1} / \mathrm{YM}_{2}\right)$ o volume médio de viagens nos dias da semana (desconsiderando-se as viagens no dia de maior pico).

Analisando-se os dois períodos de forma distinta, observou-se que o melhor coeficiente de determinação $\left(R^{2}\right)$ encontrado para as equações foi 0,533 quando se considerou todos os veículos de carga e 0,737 quando se utilizou as viagens de caminhões apenas. A maior incidência dos coeficientes de determinação foi para valores menores que 0,3 valores considerados como inadequado (Stevenson, 1981). Também quando analisado o nível de significância dos coeficientes (de todas as variáveis utilizadas), para todas as equações, constatou-se que estas não possuem níveis de confiança desejável, ou seja, entre $90 \%$ e $99 \%$.

Portanto, nenhuma das equações inicialmente obtidas pode ser considerada representativa como função de demanda de veículos de carga para os shopping centers pesquisados. Sendo assim, partiu-se para outro tipo de análise, considerando o intercepto nulo na função resultante, ou seja, passando pela origem. Dentro deste conceito, foram considerados como variáveis independentes: área construída, área bruta locável e o número médio de clientes.

Estas variáveis foram escolhidas considerando-se a lógica de que, se a variável independente " $X$ " (área construída, área bruta locável e/ou número de clientes) for igual a zero, ou seja, "não existe shopping center", também "não existe movimento de vendas no shopping center" e conseqüentemente, a variável dependente "Y" (volume de veículos de carga demandados) também será igual a zero.

Com base nesta lógica, todas as equações resultantes apresentaram coeficientes de determinação $\left(\mathrm{R}^{2}\right)$ superiores a 0,9 (considerados adequados por serem maiores que 0,7 (Stevenson, 1981)), tanto para os dois períodos analisados, como para as duas situações: (1) todos os veículos de carga ou (2) somente para caminhões, porém, os coeficientes de algumas equações não apresentaram significância estatística. Sendo assim, foram destacadas as equações apresentadas na Tabela 8 por serem estatisticamente significantes, com base no teste $t$ e no valor-p, e com níveis de confiança variando entre $95 \%$ e $99 \%$. Observe-se que estas são as equações que têm como variável independente a área construída e o volume médio de cliente e como variável dependente volumes de viagens considerando todos os veículos. Nestas equações o valor de $t$ variou entre 2,23 a 3,40, em relação a variável "área construída” e entre 4,11 e 5,90 em relação a variável número "médio de clientes".

\section{CONSIDERAÇÕES FINAIS}

A motivação para desenvolvimento deste estudo veio da necessidade de buscar soluções para os problemas de tráfego que possam surgir com a implantação de empreendimentos como os supermercados e shopping centers.

Tabela 8. Equações estatisticamente significantes com duas variáveis

\begin{tabular}{|c|c|c|c|c|c|}
\hline $\begin{array}{l}\text { Variável dependente } \\
\text { (Y) }\end{array}$ & & $\begin{array}{l}\text { Variável independente } \\
\qquad\left(X_{i}\right)\end{array}$ & Equação & $R^{2}$ & \\
\hline $\begin{array}{l}\text { Volume de veículos na semana } \\
\text { (dezembro) }\end{array}$ & $\begin{array}{l}\mathrm{X}_{2}: \\
\mathrm{X}_{9}:\end{array}$ & $\begin{array}{l}\text { área construída } \\
\text { volume médio de clientes }\end{array}$ & $Y=0,00076 X_{2}+0,00475 X_{9}$ & 0,973 & (15) \\
\hline $\begin{array}{l}\text { Volume médio de veículos fora do } \\
\text { dia pico (dezembro) }\end{array}$ & $\begin{array}{l}\mathrm{X}_{2}: \\
\mathrm{X}_{9}:\end{array}$ & $\begin{array}{l}\text { área construída } \\
\text { volume médio de clientes }\end{array}$ & $Y=0,00012 X_{2}+0,00055 X_{9}$ & 0,969 & (16) \\
\hline $\begin{array}{l}\text { Volume de veículos na semana } \\
\text { (março) }\end{array}$ & $\begin{array}{l}\mathrm{X}_{2}: \\
\mathrm{X}_{9} \text { : }\end{array}$ & $\begin{array}{l}\text { área construída } \\
\text { volume médio de clientes }\end{array}$ & $Y=0,00055 X_{2}+0,00322 X_{9}$ & 0,980 & (17) \\
\hline $\begin{array}{l}\text { Volume de veículos no dia pico } \\
\text { (março) }\end{array}$ & $\begin{array}{l}\mathrm{X}_{2}: \\
\mathrm{X}_{9}:\end{array}$ & $\begin{array}{l}\text { área construída } \\
\text { volume médio de clientes }\end{array}$ & $Y=0,0014 X_{2}+0,00063 X_{9}$ & 0,984 & (18) \\
\hline $\begin{array}{l}\text { Volume médio de veículos fora do } \\
\text { dia pico (março) }\end{array}$ & $\begin{array}{l}\mathrm{X}_{2}: \\
\mathrm{X}_{9}:\end{array}$ & $\begin{array}{l}\text { área construída } \\
\text { volume médio de clientes }\end{array}$ & $Y=6,897^{(E-5)} X_{2}+0,00043 X_{9}$ & 0,977 & (19) \\
\hline
\end{tabular}


Para tanto, as equações encontradas possibilitam fazer uma estimativa das viagens atraídas e, conseqüentemente, fazer uma previsão do impacto dos veículos de carga na área de influência dos mesmos. Foram apresentadas 19 equações utilizando-se diferentes variáveis explicativas que permitem fazer diferentes análises da demanda de um empreendimento a ser implantado. Porém, estas equações devem, a princípio, ser utilizadas para a cidade do Rio de Janeiro e, possivelmente, para cidades que tenham características similares.

Observe-se que as variáveis explicativas que se mostraram relevantes neste estudo estão mais relacionadas com a operação dos supermercados e shopping centers do que com as características físicas. No caso dos supermercados, as equações resultantes e com maior coeficiente de determinação tinham as variáveis "número de clientes" e/ou "número de funcionários" como variáveis explicativas; no caso dos shopping centers, a variável "número de clientes" entrou como variável independente nas equações resultantes e de maior significância, assim, para uma estimativa da demanda de viagens de veículos de carga, parece ser necessário uma estimativa da demanda de clientes assim, como do número de funcionários.

Entretanto, considera-se interessante pesquisar um conjunto maior de empreendimentos e observar se é possível definir modelos segundo uma classificação ou característica física de shopping centers e supermercados.

Acredita-se, também, que a ampliação da pesquisa e considerando outras cidades, possibilite encontrar outras variáveis relevantes e que talvez associadas às características físicas do empreendimento possam resultar em equações com valores de coeficiente de determinação mais aceitáveis.

\section{AGRADECIMENTOS}

Ao CNPq e a FAPERJ pelo apoio a Rede Ibero Americana de Estudos em Pólos Geradores de Tráfego- Rede PGV ( http://redepgv.coppe.ufrj.br). A CAPES, pelo fornecimento de uma bolsa de mestrado para o desenvolvimento da pesquisa que resultou neste trabalho.

\section{REFERÊNCIAS BIBLIOGRÁFICAS}

Gasparini, A. (2008) Atratividade do Transporte de Carga para Pólos Geradores de Viagem em Áreas Urbanas. Dissertação de Mestrado. Instituto Militar de Engenharia. Rio de Janeiro

Hutchinson, B. G. (1974) Principles of Urban Transport Systems Planning. Scripta Book Company. USA.

ITE, Institute of Transportation Engineers (2001) Trip Generation, Sexta Edição. Washington D.C.

ITE, Thecnical Council Committee (1995) Truck Trip Generation, Washington D. C.

Melo, I.C.B. (2002) Avaliação da demanda por transporte de carga em áreas urbanas, Dissertação de Mestrado. Engenharia de Transportes do Instituto Militar de Engenharia, Rio de Janeiro.

Ogden, K. W. (1992). Urban Goods Movement, a Guide to Policy and Planning. Editora Ashgate, England-UK.
Portugal, L. S. e Goldner L. G. (2003) Estudo de Pólos Geradores de Tráfego e de seus Impactos nos Sistemas Viários e de Transportes. Editora Edgard Blücher Ltda. São Paulo/SP.

Silva M. R. e Waisman, J. (2007) Cargas Urbanas: Estudo Exploratório sobre a Geração de Viagens de Caminhões em Bares e Restaurantes. Anais do $16^{\circ}$ Congresso da ANTP, Maceió, AL

Stevenson, W. J. (1981) Estatística Aplicada à Administração. São Paulo, Editora Harbra Ltda. 